\title{
The Spiral Movement of the Sun on an Imaginary Cylinder According to Empedocles and Anaximander
}

\section{Dirk L. Couprie}

University of West Bohemia, Faculty of Arts, Department of Philosophy, Sedlackova 19, 306 14, Pilsen, Czech Republic (retired); dirkcouprie@dirkcouprie.nl

For citation: Dirk L. Couprie. The Spiral Movement of the Sun on an Imaginary Cylinder According to Empedocles and Anaximander. Philologia Classica 2020, 15 (1), 4-24.

https://doi.org/10.21638/spbu20.2020.101

This article discusses an intriguing text in Stobaeus' Ecl. 1.25.3i about the sun's movement as a spiral on a cylinder. The author offers an interpretation of this text and argue that it is about Empedocles' conception of the solar trajectory during the year. After a preliminary attempt, an interlude is inserted on some strange theories, ascribed to Empedocles, about the two hemispheres of the heaven and two suns. Two of the more reliable theories attributed to Empedocles that are relevant in the context of this paper, namely the tilting and the eggshape of the heaven, as well as the problems of the size of the sun and the shape of the earth, are discussed in successive sections. This allows the author to illustrate some of his ideas on Presocratic flat earth cosmology. Prior to offering a visualization of the cosmos according to Empedocles, Bollack's earlier attempt is subjected to a critical examination. In two additional sections of the article, the author claims that, according to Empedocles, the moon must move on a cylinder as well and that the image of the cylinder for movements of the sun and moon dates back to Anaximander.

Keywords: Empedocles, Anaximander, Presocratics, cosmology, Sun (movement of), cylinder, spiral.

\section{Introduction: The sun spiraling on a cylinder ${ }^{1}$}

At first glance, an anonymous text hidden in the Addenda of the Doxographi Graeci ${ }^{2}$ looks like the expression of a troubled mind. I will show that it is rational and makes perfect sense in the context of Presocratic cosmology. It reads as follows:

${ }^{1}$ Many thanks for their critical and helpful remarks to Rosemary Wright, Vojtěch Hladký, Radim Kočandrle, Mathieu de Bakker, my brother Leendert D. Couprie, and an anonymous reviewer.

2 Dox. 853; see also Wachsmuth 1884, 211 and MR 555, n. 403.

(C) St. Petersburg State University, 2020 


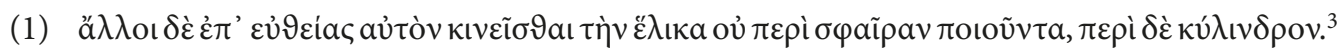

But others say that its (i.e. the sun's) movement creates a spiral in a straight line, doing this not on (the surface of) a sphere, but on (the surface of) a cylinder.

That the movement of the sun is rotational is already indicated by the words $\varepsilon \lambda_{\iota} \xi$ and

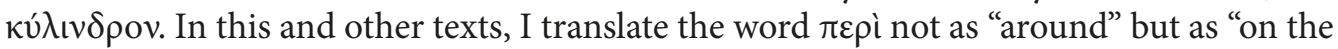
surface of", or simply "on" (in text 2, the word $\dot{\varepsilon} v$ is used instead of $\pi \varepsilon \rho \grave{\text { ) }}$. I use "around" when this movement is said to be around the earth or around the celestial axis. The ex-

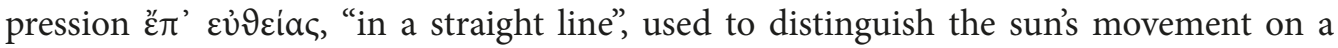
cylinder from its movement on a sphere, will be explained below, when text 6 is discussed

\section{The sun spiraling on a sphere}

Text 1 must be understood in relation with the immediately preceding one, which I will discuss first.

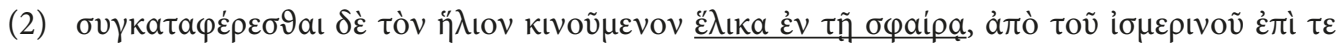

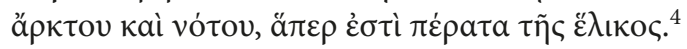

And the sun as it moves produces a spiral on the sphere, from the equinoctial (circle) to both the northern and the southern (tropics), which are the limits of the spiral.

Text 2 can be visualized by Fig. $1 \mathrm{~A}$ and $1 \mathrm{~B}^{5}$ :

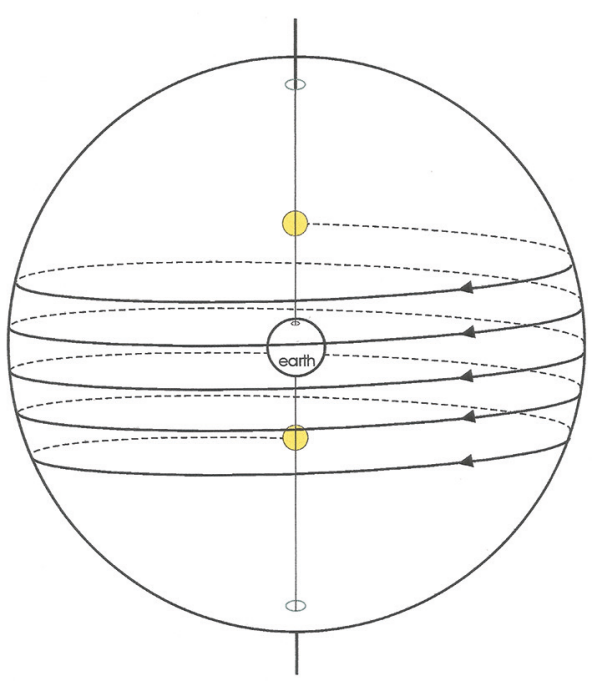

Fig. 1A. The sun's spiral on a sphere

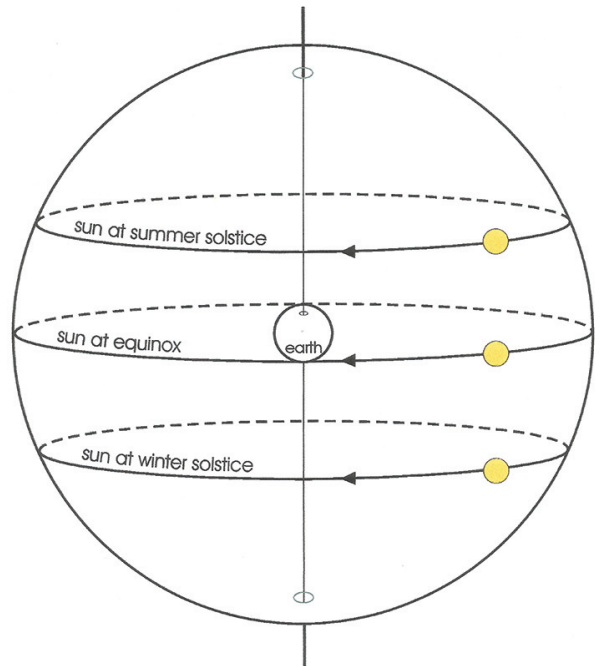

Fig. 1B. The sun's paths on a sphere during the solstices and equinox

${ }^{3}$ Stob. Ecl. 1.25.3i, cf. MR 554 and 560-561.

${ }^{4}$ See Dox. 853, Stob. Ecl. 1.25.3i, MR 554 and MR 560-1. All drawings are made by the author.

5 Similar pictures with six upward and downward windings recently appeared in an instructive book on astronomy: Mulder 1994, 33, Fig. 19: "Sonnenspirale". 
In Fig. 1A, the sun must be thought to orbit around the earth from east to west in one day and to spiral on the sphere around the celestial axis during the year downwards from its northernmost position to the southernmost and then back up again. Only a downward spiral has been drawn. To correctly represent the half year movement of the sun, one should imagine 182.5 curves of the downward spiral, instead of the five drawn here, and another 182.5 curves of an upward spiral. ${ }^{6}$ This has not been done here in order not to overload the picture. With so many windings, the daily path of the spiraling sun looks like a complete circle. Hence, in Fig. 1B, three positions of the sun are drawn as circles. It should be noted that the orbit of the sun varies in width, being wider during the equinoxes than during the solstices.

In Stobaeus' book, texts 1 and 2 follow immediately after a text on Cleanthes about the question of where the sun gets its nutrition from. We will discuss that text later on (text 4).

\section{Two explanations of the sun's movement: The spiral versus the ecliptic}

Mansfeld and Runia argue that texts 1 and 2 "are plainly formulated to stand in opposition to each other". Text 2 "appears to assume the dominant geocentric spherical model of the universe which also forms the basis for the Platonic-Pythagorean" cosmological concept, while text 1 reminds them of an earlier doxa on Empedocles. ${ }^{7}$ According to them, "these [two] doxai add little to the chapter (...), they may have been tacked on. (...) we cannot be certain that these lemmata belong to the original chapter", i.e. Aëtius $2.23 .^{8}$ They "amount to a kind of rehash of the contrast between Empedocles and Plato-Pythagoras-Aristotle". ${ }^{9}$ Although they believe that text 2 "appears to continue the views of the Stoics", they prefer to regard text 1 "as a separate lemma, because [it] forms a deliberate contrast"10

In general lines, I accept these conclusions. In my opinion, however, the contrast between the two is not "between a (mechanical) vortex model (...) and a (teleological) centrifocal model". ${ }^{11}$ Since texts 1 and 2 use the same image of the spiral, they do not differ as vorticial versus centrifocal, but simply as to the shape of the body on which the sun is spiraling: a sphere in text 2 and a cylinder in text 1 . Both texts describe the movement of the sun in a way that contrasts with what has become the standard explanation of the Post-Platonic system. In this system, the movement of the sun is explained by the combination of two movements, one from east to west, like the stars, and the other from west to east along the ecliptic (or, as the Greeks used to say, the band of the Zodiac), the plane of which is tilted by $23.5^{\circ}$ in relation to that of the equator. This is formulated in a previous item in the same chapter of Aëtius, in which the turnings of the sun are described using the notion of the obliquity of the ecliptic as represented on an armillary sphere:

6 The half year from the autumnal to the vernal equinox counts about seven days less than the half year from the vernal to the autumnal equinox. This is just a question of counting days and was probably known to the ancient Greeks. But because the texts are silent about this, I disregarded it.

7 MR 557.

8 MR 558 and 559.

9 MR 558.

10 MR 557 and 558.

11 MR 557. 


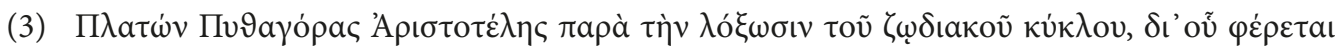

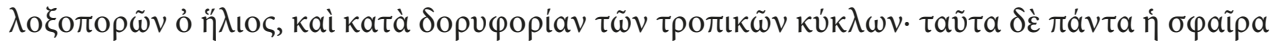
$\delta \varepsilon \dot{\kappa} \kappa \nu \cup \sigma{ }^{12}{ }^{12}$

Plato, Pythagoras and Aristotle (declare that the turnings of the sun result) from the tilting of the zodiac circle, through which the sun moves in an oblique course, and in virtue of the flanking of the solstitial circles. All these matters the sphere demonstrates well.

Texts 1 and 2, on the other hand, describe the movement of the sun without using the concept of the ecliptic. They, too, explain the movement of the sun by the combination of two movements, one from east to west, like the stars, but slower than these, and another from north to south and back again between the two tropics. ${ }^{13}$ The result of these two movements is a spiral. The explanation by means of the image of a helix and without the concept of the ecliptic is probably ancient, as it is less sophisticated than the explication by means of the ecliptic and its obliquity. It is based on the simple observation that each day the sun rises and sets somewhat further to the south or north than the previous day. The explanation in text 3, however, states that the sun during the year moves from one constellation of the Zodiac to another. This is not based on direct observation, but on deduction and calculation, because by day we do not see the stars and at night we do not see the sun.

In general terms, the Stoics accepted the Platonic-Aristotelian cosmology. If text 2 is to be considered Stoic, we must conclude that it does not use the standard interpretation but an anachronistic description of the movement of the sun. text 2 speaks of "a spiral

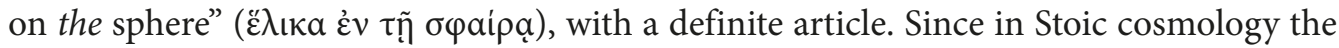
celestial bodies are located below the celestial sphere of stars at various distances from the earth, the sphere on which the sun spirals cannot simply be identified with the celestial sphere. The idea is that sun, moon, and planets each have their own spheres (more precisely: sphere shells), to which they are attached, whether they are real spheres, as in Aristotle, or imaginary spheres. Another interpretation could be that the words "on the sphere" are meant to indicate that movement of the sun is explained against the background of the celestial sphere.

\section{Why should the spiral movement on a sphere stop?}

The Greeks spoke of the turnings ( $\tau \rho$ ó $\pi$ o ) of the sun, because during the solstices the sun, having arrived at the tropics, appears to reverse in its yearly north-south movement and vice versa. There seems to be no reason, however, why the sun should stop exactly there and not continue spiraling until it has reached one pole of the sphere, and then return until it has reached the opposite pole, and so on. The Stoics tried to explain these turnings by assuming that the sun lacks sufficient nutrition from the exhalations of the earth or the ocean:

12 Aëtius in Pseudo-Plut. Plac. 2.23.6. Not in DK or LM, but see Dox. 353; see also MR 552 and 5601. "Pythagoras" must be understood as "later Pythagoreans". This text concentrates on the explanation of the solstices by means of the obliquity of the ecliptic, ignoring the differences between the three systems. Plato, for example, uses the ancient image of the spiral movement ( $\tilde{\varepsilon} \lambda_{\iota} \xi$, Tim. 39a5) next to the image of the movements of the Same and the Different.

13 See several sources in DK 41A7. 


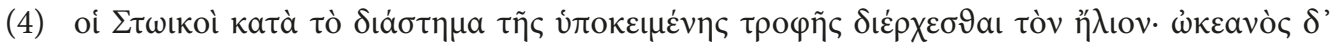

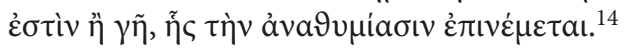

The Stoics (declare that) the sun's course is determined by the distance covered in accordance with the food available to it. This is the ocean or the earth, from which the sun consumes exhalation.

As we shall see at the end of this paper, this explanation has Presocratic roots. Another text describing Cleanthes' opinion only mentions the ocean:

(5) solis meatus a plaga quae usta dicitur non recedit quia sub ipsa currit Oceanus qui terram et ambit et dividit, omnium autem physicorum adsertione constat calorem umore nutriti. ${ }^{15}$

The sun's journey does not depart from the so-called "torrid" zone, under which the Ocean runs, circling the earth and marking its limits; and the physical scientists universally hold that heat is fed by moisture.

This text is a somewhat strange mixture of old (the encircling Oceanus, the sun fed by moisture) and new ideas (spherical earth). The text says that the Ocean is situated under the torrid zone. This implies that the "torrid zone" is not a zone on the earth, but in the heavens on both sides of the celestial equator, between the Tropic of Cancer and the Tropic of Capricorn. ${ }^{16}$ The obvious meaning is that the sun's movements are limited by the banks of the river Ocean, which is supposed to run around the terrestrial equator of the spherical earth, dividing it in two hemispheres. The Ocean lies under the torrid zone, one of its banks under the northern tropic, the other under the southern tropic. ${ }^{17}$ The last line of text 5 suggests that Cleanthes elaborated on the Presocratic idea that the sun has originated from and is fed by moisture from the earth, but a discussion of that idea falls outside the scope of this paper. ${ }^{18}$ We may conclude that the Stoic answer to the question of why the sun returns at the solstitial circles does not sufficiently clarify why these turnings always happen on precisely the same times of the year and at exactly the same places on the celestial vault.

\section{The sun spiraling on a cylinder, and the ideas behind it}

We may wonder why the anonymous people in text 1 felt that the movement of the sun is better represented by the image of a spiral on a cylinder than that of a spiral on a sphere. One consideration could have been that the image of the sun spiraling on the sphere raises the question of why in summer this movement of the sun always stops ex-

14 Aëtius 2.23.5, see Dox. 353 and MR 560-561, Reconstructed text 2.23.7.

15 Macrob. Sat. I. 23.2, partially in DK 31B41.

16 Cf. Aëtius 2.12.1 = DK 11A13c=LM THAL. R23, where it is said that according to (Thales and) Pythagoras and his disciples "the sphere of the entire heaven has been divided into five circles to which they gave the name 'zones': the arctic or always appearing, the summer tropic, the equatorial, the winter tropic, and the antarctic and invisible". In the same sense, Parmenides is said to have marked of the inhabitable places of the earth under the two tropical zones (Ps.-Plutarch, Plac. 3.11.4=DK 28A44a=LM PARM. D39 (Graham 2010, 227, Parm 44, translates, less correctly, "defines (...) in relation to". Aristotle speaks of the uninhabitable lands in the far north as "beneath the Bear" (Mete. 362b9) and refers to the northern limit of the inhabitable part of the earth as "the ever-visible circle" (Mete. 362b38).

17 Furley's explanation probably tries to say the same. He states "that the solstices are due to the fact that the sun needs food, his food comes from the Ocean, so he turns back when he reaches the southern and northern limits of the Ocean". (Furley 2005, 448).

18 See for a thorough discussion Kočandrle 2019. 
actly at the northern tropic and in winter exactly at the southern tropic. In the previous section, we have seen that the answer that the sun turns back by lack of moisture as its nutrition is not very convincing.

Quite another, inventive and surprisingly reasonable answer to the question of why the sun's movement is limited by the tropics is given in text 1 . In the image of the cylinder within a sphere, it is immediately clear why and where the northward and southward movement of the sun has to stop and the sun is forced to return: the upward movement of the sun is obstructed by the northern part of the sphere and the southward movement by its southern part, always on the same dates of the year. Text 6 provides the answer to the question of who imagined a spiral movement of the sun on a cylinder:

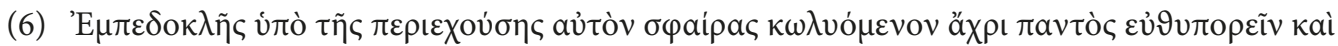

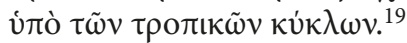

Empedocles (declares that the turnings of the sun are caused) by the sphere that surrounds it and which inhibits it to continue its course in a straight line, and by the solstitial circles.

The shape of the cylinder is not directly mentioned in text 6 , but is implied by the

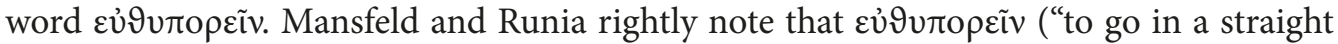
line") echoes the words ' $\dot{\pi}{ }^{\prime}$ ' $\dot{v} 9$ cias of text $1,{ }^{20}$ emphasizing the yearly up and down movement of the sun along the side of an imaginary cylinder. The word $\varepsilon \dot{v} 9 v \pi$ opeiv is reinforced

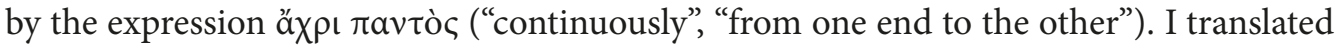

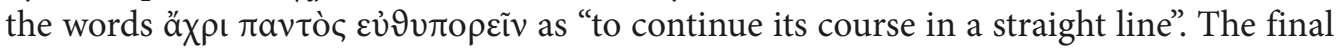
words "and by the solstitial circles", with a kai explicativum, make it perfectly clear where the spiraling movement stops and turns back.

As we have seen in Figs. 1A and 1B, the spiraling motion of the sun on a sphere entails that its daily orbit during the solstices is less wide than that at the equinoxes. A second reason for the image of the cylinder could have been that it seems more rational that the curves of the spiral do not differ in width but are all equally wide. This is expressed by the

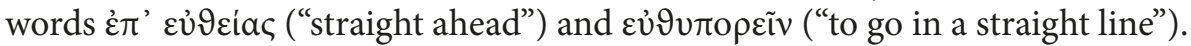

In text 1 , the sphere was meant as the (real or imaginary) sphere, on which the sun spirals (see Figs. 1A and 1B). The cylinder, however, on which the sun spirals (see Figs. 2A and $2 \mathrm{~B}$ ) is by no means a real object but is purely imaginary. The sphere in text 6 and in Figs. $2 \mathrm{~A}$ and $2 \mathrm{~B}$, on the other hand, if it is able to stop and reverse the spiral motion of the sun, must be a physically real and not an imaginary sphere. This consideration also points to Empedocles, who is said to have conceived of the heaven as:

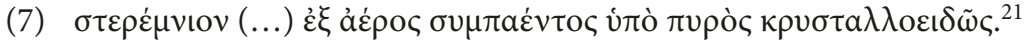

solid (...), consisting of air that has been compacted together by fire like crystal.

We may conclude that the "sphere that surrounds the sun" in text 6 must be the crystalline celestial sphere of text 7 and not the sphere of the sun as in text 2 . This conception, in which the sun is said not to spiral on a sphere but on a cylinder, can also be illustrated. In Figs. 2A and 2B, I have drawn a preliminary draft of this conception; final pictures will be offered later in Figs. 5A, 5B, and 6.

\footnotetext{
19 Aëtius 2.23.3 = DK31 A58 = LM EMP. D130.

20 See MR 557.

21 Aëtius 2.11.2. = DK 31A51 = LM EMP. D118.
} 


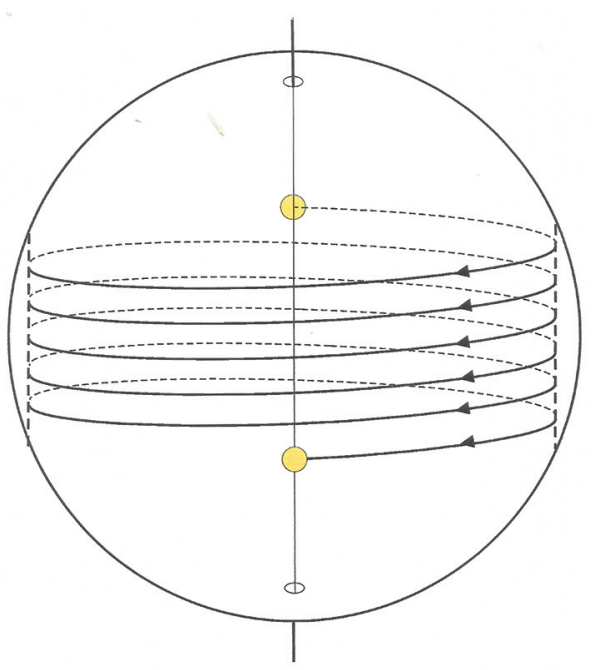

Fig. 2A. The sun's spiral on a cylinder

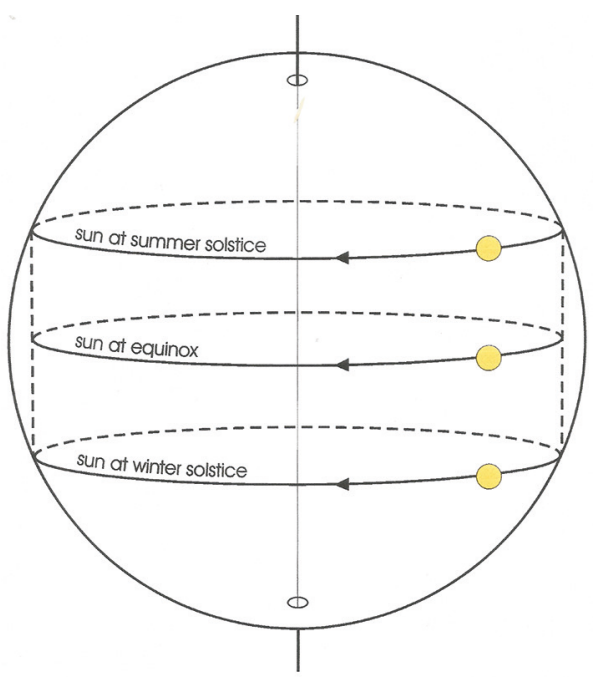

Fig. 2B. The sun's paths on a cylinder during the solstices and equinox

The combined texts 6 and 7 allow us to fill in the name of Empedocles for the anonymi of our text 1 . According to Empedocles, the sun, circling on the surface of an imaginary cylinder, is hindered in its up and down movement twice a year, in summer and winter, by the solid crystal of the celestial sphere. This explains why the sun's movement always reverses its course at exact the same positions on the starry sky, which are called the Tropic of Cancer and the Tropic of Capricorn. The crystalline celestial sphere is the sphere of the stars:

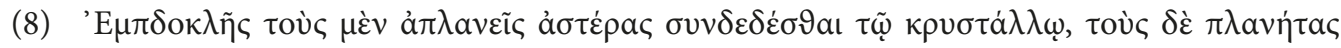
$\dot{\alpha} v \varepsilon \tilde{\sigma} \sigma 9 \alpha .^{22}$

Empedocles says that the fixed heavenly bodies became fastened to the crystalline (heaven), while the planets are unfastened.

The implication of this is that the sun is never far away from the stars and during the solstices even orbits among the fixed stars, while the planets should be imagined to wander among the fixed stars on the crystalline vault. Kingsley also concluded from DK 31A58 (text 6), that Aëtius "portrays Empedocles' sun as a distinct cosmic body following its own orbit just inside the surrounding celestial vault". ${ }^{23}$ This interpretation is confirmed by a somewhat cryptic text:

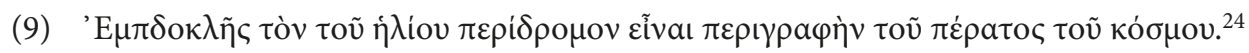

Empedocles (says that) the orbit of the sun is the circumference of the limit of the cosmos.

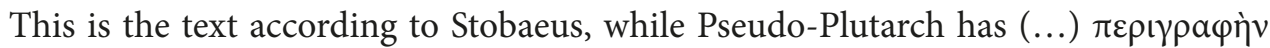

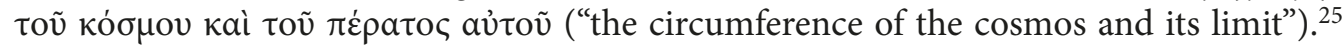
In the image of the sun spiraling on an imaginary cylinder, the orbit of the sun cannot

22 Aëtius 2.13.11 = DK 31A54 = LM EMP. D121b.

23 Kingsley 1994, 318.

24 Aëtius 2.1.4 = DK 31A50 = LM EMP. D129.

25 See MR 306 and Bottler (2014) 287. Dox. 328, however, gives the same text in Pseudo-Plutarch as in Stobaeus. 
literally be called the circumference of the limit of the cosmos during the whole year, but only during the solstices (see Fig. 2B). Therefore, I take text 9 to mean that the sun, at the end (or better: at both ends) of its course on the imaginary cylinder describes a circle ( $\pi \varepsilon \rho ү \rho а \varphi \eta \dot{)}$ on the screen of the crystalline vault, as if the text sounded: 'Е $\mu \pi \delta$ oк $\lambda \tilde{\eta} \varsigma$

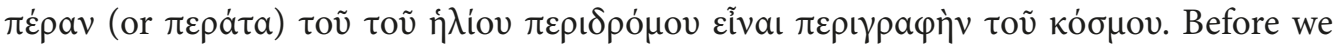
can draw an impression of the cosmos according to Empedocles with the sun spiraling on a cylinder, we must discuss some more cosmological details.

\section{Two hemispheres and two suns?}

Another cryptic text mentions as Empedocles' opinion that there are two suns. The first is an archetypal fire in one of the two hemispheres of the celestial vault, while the other, which we call the sun and which is opposite the first one, is its reflection via the earth on the other hemisphere of the crystalline vault:

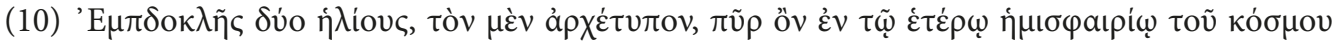

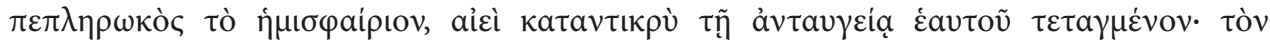

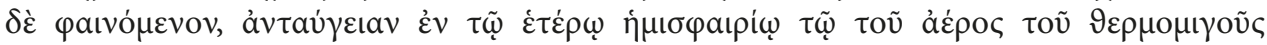

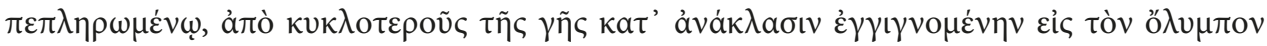

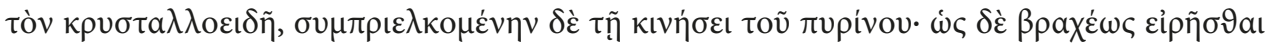

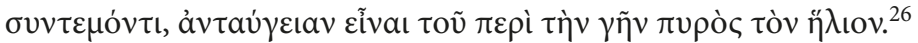

Empedocles (declares that there are) two suns: on the one hand (there is) the archetype, which is fire in the one hemisphere, always stationed opposite its own reflection; on the other hand (there is) the visible sun, which is its reflection in the other hemisphere, namely the one filled with air mixed with heat, arising from the circular earth through a reflection onto the crystal-like Olympus (i.e. heaven), and carried around with it by the motion of the fiery (element); to sum up in a brief phrase, the sun is a reflection of the fire around the earth.

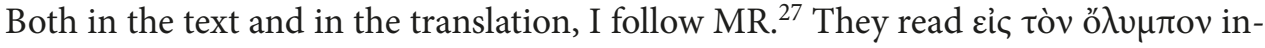

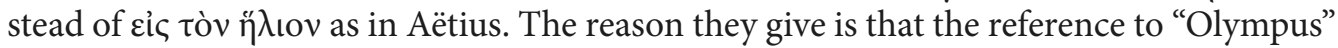
goes back to the Arab translation by Qusțā Ibn Lūqā, who "will not have made this up". Elsewhere, Olympus is also the name for heaven. ${ }^{28}$ This emendation is in line with the usually accepted meaning of text 11, the last words of which form a genuine Empedocles fragment:

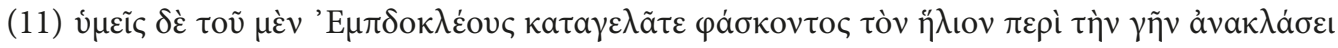

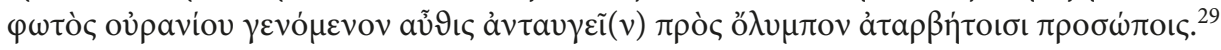

You (Stoics), however, ridicule Empedocles, who says that the sun, originated by reflection of the light of the heaven around the earth, again shines back onto Olympus (i.e. the heavenly vault) with fearless countenance.

26 Aëtius 2.20.13= DK 31A56 = LM EMP. D126a. McKirahan 2010 wisely ignores this text.

27 MR 530 and 532.

28 See MR 520, n. 354; see also Mansfeld 1986, Empedocles 58. LM EMP. D126a also adds between brackets after "Olympus": "i.e. the celestial vault". For "Olympus" as a mythological name for heaven, see DK 44A16 (Philolaus) and DK 28B11 (Parmenides).

29 Plut. De Pyth. Or. 12, 400b = DK 31B44=LM EMP. 123. 
In the Wortindex of DK, s.v. ö $\lambda \nu \mu \pi$,

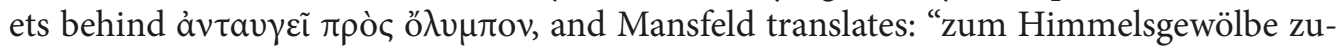
rückstrahlt". ${ }^{30}$ The concepts of the two hemispheres, one of the night and one of the day, and the sun as a reflection appear also in another text:

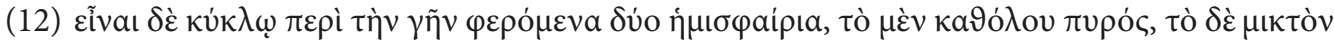

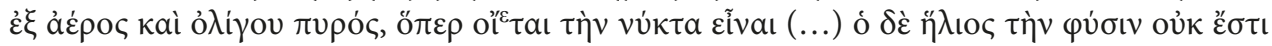

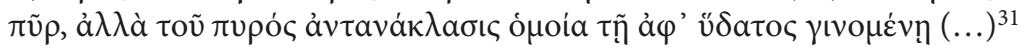

There are two hemispheres that move in a circle around the earth, the one is entirely of fire, the other is a mixture of air and a little bit of fire, which he thinks is the night (...) The nature of the sun is not fire, but the reflection of fire, similar to the one produced by water (...)

A thorough discussion of Empedocles' supposed theories of the two suns and the two hemispheres falls outside the scope of this paper. I will discuss them only insofar as needed in the context of its main subject, which is the movement of the sun on an imaginary cylinder. I agree with Kingsley and Wright that text 10 as it stands is nonsensical and absurd. ${ }^{32}$ The same can be said of Plutarch's interpretation of Empedocles' words in text 11 and Pseudo-Plutarch's version in text 12. Even if one does not agree with all the arguments Kingsley and Wright bring forward, at least the three following are convincing. The first is about the two suns and the one we see as a reflection. As Wright puts it: "all the [genuine] sun fragments refer clearly to the sun we know", ${ }^{33}$ without any trace of another, archetypal sun. The second is about the alleged two hemispheres, one of the night and one of the day, and comes from another genuine fragment. In Wright's words: "Empedocles' understanding of the cause of night is authenticated by this line (i.e. text 13) and is therefore preferable to the 'hemisphere of air' theory in the doxographical transmission from

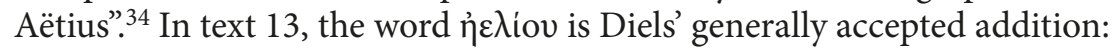

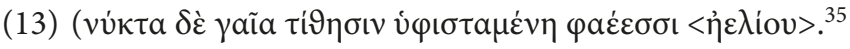

The earth makes the night by obstructing $<$ the sun's $>$ rays.

The third argument is that text 10 "is (...) contradicted by the simplest observation". ${ }^{36}$ One of the absurdities contradicted by simple observation is that during sunrise and sunset we should see one half of the hemisphere of day and one half of the hemisphere of night, which obviously is not the case. Another is that a reflection as described in text 10 is

30 Mansfeld 1986, Empedocles 59. Similarly Gemelli Marciano 2013, Emp. 70. See also Bollack 1992, III, 268; Wright 2001, 201. Exceptions are Graham 2010, 371, Emp. 75 and McKirahan 2010, 244, 14.92, who translate "the sun shines back to(ward) Olympus".

31 Pseudo-Plut. Strom.10 = DK31A30 = LM EMP. D97 and D127.

32 See Kingsley 1994, 316 (“nonsensical”); Wright 2001, 201 and 202 (“absurd”).

33 Wright 2001, 202.

34 Wright 2001, 204; see also Kingsley 1994, 319.

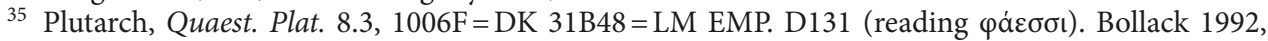
III, 278-279 tries in vain to explain this genuine fragment by means of Aëtius' interpretation in DK 31 A56 (text 10). Guthrie 2003, 195, agrees that text 13 is incompatible with text 10 and states "that Empedocles believed the dark effect of the nocturnal hemisphere to be ensured by the screening off of the sun's light by the earth".

36 Wright 2001, 202; see also Kingsley 1994, 319. 
impossible. ${ }^{37}$ Perhaps there is a confusion with Philolaus' sun receiving the reflection of the central fire. ${ }^{38}$

Summarizing, I assume that the theory of the two suns and the theory of the two hemispheres are erroneously attributed to Empedocles, who probably said no more than that the sun is a large aggregate of fire ( $\pi \cup \rho o ̀ \varsigma ~ a ̈ 9 \rho o ı \sigma \mu \alpha \mu \dot{\varepsilon} \gamma \alpha$ ), as Diogenes Laërtius puts it, ${ }^{39}$ while night is caused by the earth's blocking the light of the sun (see text 13).

\section{Shape and tilt of the cosmos according to Empedocles}

In the previous pages, the words "celestial sphere" have been used literally. This must be slightly adapted, because Empedocles is said to have thought that the heaven was eggshaped:

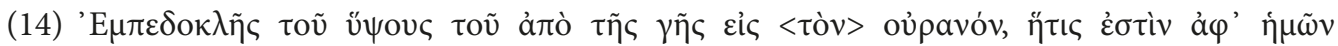

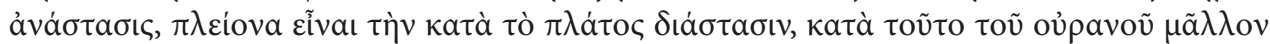

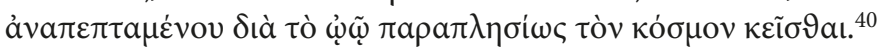

Empedocles says that larger than the height from the earth to the heaven, which is its distance from us, is its measure in breadth; in this direction, the heaven is more elongated since the cosmos is shaped like an egg.

Empedocles will probably not really have meant the shape of an egg with one end more tapered than the other, but the three-dimensional shape of an oval turned around its major axis that is called by the technical terms "ovoid", or "ellipsoid", or "oblate spheroid", i.e., an elongated sphere. No explanation is given as to why he chose this shape; we can only speculate.

Empedocles is also one of those Presocratics, of whom it is reported that they thought that originally the celestial axis stood perpendicular on the earth's surface but that in the course of the cosmogony the heavens had been tilted. ${ }^{41}$ This was described as a tilt of the pole, or the poles, or the cosmos, or the stars, or the heavens, all of which boils down to the same thing.

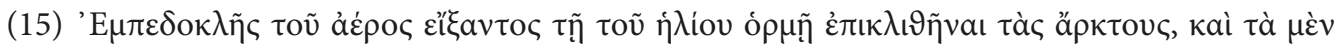

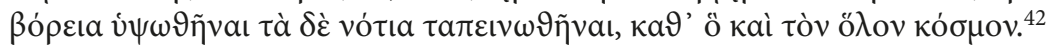

According to Empedocles, the air having yielded to the drive of the sun, the poles became inclined and the north (of the heaven) went up while the south went down, and accordingly the whole cosmos.

The words $\tau$ àc ă Bear and Little Bear), meaning the visible pole, or the two poles of the heavens. Here I

37 See Kingsley 1994, 316.

38 Cf. Aëtius 2.20.12=DK 44A19= LM PHILOL. D22.

39 See Diogenes Laërtius 8.77= DK 31A1(77) = LM EMP. D128.

40 Aëtius in Stobaeus, Eclog. 1.26.5 = DK 31A50 = LM EMP. D119.

41 The others were Anaxagoras (DK 59A1(9), DK59A67), Diogenes (DK 59A67), Archelaos (DK 60A4(4)), and probably Anaximander (DK 12A22, the wheels of sun and moon lying aslant) and Anaximenes (DK 13A7(6), the cap simile).

42 Aëtius 2.8.2 =DK 31A58=LM EMP. D120 (reading $\dot{\varepsilon} \gamma \kappa \lambda เ 9 \tilde{\eta} v a$; see also Dox. 338, note at line 6 of the left column, MR 409, 310, and 414, Bottler 2014, 334). Bottler (2014, 335) wrongly supposes that a dip of the earth is meant. 
chose for the latter, because for Empedocles the sphericity of the heavens (with the nuance discussed above) was an established fact. It has been argued that the phrase "the north (of the heaven) went up while the south went down" must be a doxographer's misunderstanding, since the idea is that originally the (north) pole was in the zenith, while the celestial axis had been tilted during the cosmogony, which is most naturally called a downward tilting of the visible (north) pole. ${ }^{43}$

How "the air having yielded to the drive of the sun" could be meant as the cause of the tilting of the heavens I do not understand.$^{44}$ It is also not immediately clear how these two features - the egg-shape and the tilt of the heaven - relate to each other. We may assume that the egg-shape evolved from the original sphere during the process of cosmogony before the heavenly vault got its crystalline nature. We may also assume that the cosmos tilted at a later stage of cosmogony. Two questions remain, however. The first is whether the egg-shaped cosmos before its tilting must be imagined as lying or standing. Bollack seems to be hesitant about this, since in his main image he chooses for an initially standing egg, but in another picture, he draws an initially lying egg (both pictures not reproduced here). ${ }^{45}$ Text 14 seems to suggest that in the present situation we have to imagine the eggshaped heaven lying down, but this is hard to combine with a tilted celestial axis, because in that case the tilted celestial axis would not coincide with the long axis of the egg-shaped heaven, and the fixed stars would not move in perfect circles. I think it is more natural to imagine a cosmos that originally rotated around the long axis of its standing egg-shape. A standing egg is more likely to tip over than a lying egg. After the tilting, the egg-shaped heaven would not be lying down but tilted. Further on, we will see that in a tilted ovoid heaven the vertical distance to the heaven is also shorter than the horizontal distance as required by text 14 . The second question is why the cosmos is tilted by exactly a specific number of degrees. This question applies to all those Presocratics who taught the tilting of the heaven. In the doxography on Diogenes and Anaxagoras it is suggested that this was by providence, to make some regions of the earth inhabitable. ${ }^{46}$ However, this paper is not concerned with all these questions of Empedocles' cosmogony, but with its outcome: his cosmology of an egg-shaped and tilted heaven.

\section{Size of the cosmos and shape of the earth, according to Empedocles}

About the size of the cosmos we have an indication in a report of Aëtius that is handed down in two versions (texts 16 and 17):

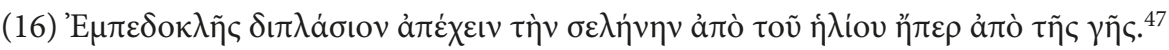

According to Empedocles, the moon is twice as far from the sun as it is from the earth.

(17) 'Е

43 See Couprie 2011, 73-74 and Couprie 2018, 28. Cf. Diogenes Laërtius 2.9=DK 59A1(9): "originally the stars moved as in a dome, so that the always visible pole was right above the earth, but later it inclined".

44 The "évolution du monde" in Bollack 1992, III, 257-260 is also incomprehensible.

45 See Bollack 1992, I, 188 and III, 259 (no. 4). Bicknell 1968, 118-119, ignores the tilting of the heavens and assumes that "the cosmos lies as an egg does when placed on a flat surface".

46 See Aëtius 2.8.1 = DK 59A67.

47 Aëtius in Pseudo-Plutarch, Plac. 2.31.1 = DK 31A61 = LM EMP. D136. See also MR 635.

48 Aëtius in Stobaeus, Ecl. 1.26.5, cf. DK 31A61 and LM EMP. D136; see also MR 635ff. 
According to Empedocles, the moon is twice as far from the earth as from the sun. ${ }^{49}$

I think Pseudo-Plutarch's version (text 16) gives the right idea. Mansfeld has convincingly argued that Stobaeus' $\tau \tilde{\eta} \varsigma$ $\sigma \varepsilon \lambda \eta \dot{v \eta} \varsigma$ (in text 17) is a case of miscopying. ${ }^{50}$ Moreover, Pseudo-Plutarch's version seems to be confirmed by a definite statement in another text:

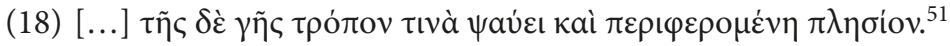

(the moon) touches the earth in a certain sense and revolves near it.

This is Plutarch's interpretation of a line of Empedocles' poem:

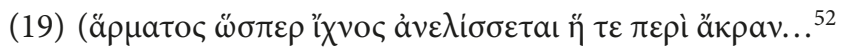

As the chariot's course turns back, around the farthest point it...

The wording of text 19 is not certain and after äkpav a number of letters are missing. ${ }^{53}$ I follow Wright's idea that the meaning probably is that the moon turns around the earth like a chariot around the post during the races, the wheel's hub almost touching the post. ${ }^{54}$ This suggests that the moon is not far away from the earth. If Plutarch's interpretation (in text 18) is right and the sun is three times as far away from the earth as the moon (see text 16), then the sun cannot be at a great distance either. And since we already concluded that the sun rotates close to (and two times a year on) the celestial vault, the cosmos, too, cannot be large. However, the closeness of the moon cannot be to the top (äkpa) of the earth, as Wright suggests. She supposes a spherical earth, but in the ancient Greek view, a moon circling around it will always be at the same distance from the earth. I think it is better to take the first meaning of the word äkpa ("farthest point", "headland", "cape"), ${ }^{55}$ which makes the comparison understandable when we imagine the moon almost touching the rim of a flat earth.

There is no text clearly stating whether Empedocles considered the shape of the earth flat or spherical. Several arguments, however, suggest that Empedocles' earth must be thought of as flat. 1) Texts 18 and 19 not only suggest a nearby moon, but also a flat earth, its rim almost being touched by the moon. 2) The tilt of the heavens (text 15) is a feature that belongs to a flat earth cosmology: it means that the celestial axis was tilted in relation to the flat surface of the earth. ${ }^{56}$ All Presocratics of whom it is told that they taught the tilting of the celestial axis ${ }^{57}$ also believed that the earth was flat. 3) In text 10,

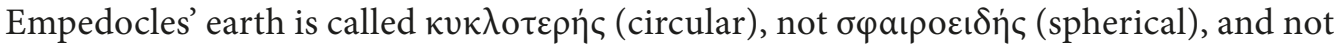

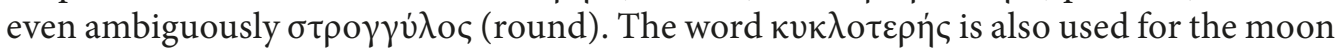
(text 21), which is elsewhere (texts 22-24) called disk-shaped. ${ }^{58}$ 4) The clear meaning

49 Translation after Bottler $(2014,481)$ and Dumont (1988), 350.

50 See Mansfeld 2000, 185 and MR 638. The emendation in Dox. 63 and in DK 59A67 (Е $\mu \pi \varepsilon \delta о к \lambda \tilde{\eta} \varsigma$

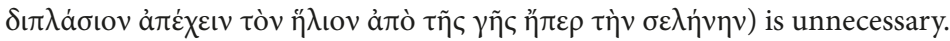

51 Plutarch, De fac. 9.925B = DK 31B46 = LM EMP. D137.

52 Ibid.

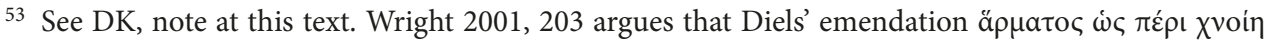

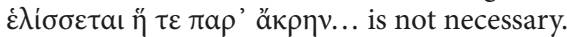

${ }^{54}$ Cf. Wright 2001, 203.

55 See LSJ, s.v. äkpa.

56 Cf. already Tannery 1887, 316 and Heath 1913, 92.

57 See note 41.

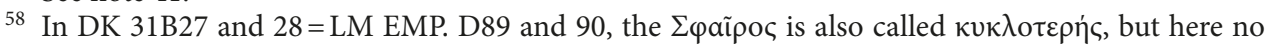
ambiguity is possible. 


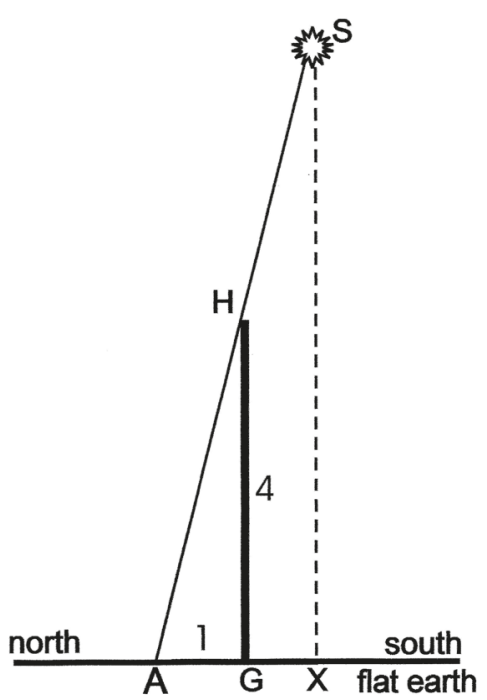

Fig. 3- On a flat earth, the sun is near (drawing not to scale) of text 14 is that the vertical distance from an observer to the ovoid heaven is less than its horizontal distance. If the earth were spherical, there would be no need for an ovoid heaven, because for an observer anywhere on the surface of a central spherical earth, the vertical distance to a spherical heaven would always be shorter than the horizontal distance. 5) The dimensions of the cosmos are rather small (see texts 16-19), which fits better with a flat than with a spherical earth. When the earth is considered flat, the sun must be close by and much smaller than the earth, about the size of the Peloponnese, as with Anaxagoras. ${ }^{59}$ The easiest way to show this is Fig 3: in Athens, at noon during the summer solstice, the shadow AG is about one fourth of the length of the gnomon HG. Consequently, the sun's distance SX must be four times the distance (AX) between Athens and the place $\mathrm{X}$ in the south where the sun is right overhead, which is on the Tropic of Cancer. Given an estimate of the distance AX of about $1500 \mathrm{~km}$, the distance of the sun, SX, will be about $6000 \mathrm{~km}$, and the size of the sun about $50 \mathrm{~km} .{ }^{60}$

This brings us to the only argument for a spherical earth, which could be derived from a text about the size of the sun:

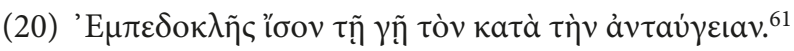

Empedocles (says that) (the sun) produced by reflection is equal to the earth.

This text has to do with Empedocles' alleged theory of the two suns discussed above. In the present context, the important issue is that it says that the sun we face is as big as the earth. A sun this size must be much farther away than possible on a flat earth and is also at odds with the dimensions of Empedocles' cosmos as a whole. ${ }^{62}$ If this text on the size of the sun is not corrupt, we must assume that Empedocles did not fully understand that on a flat earth the sun cannot be the same size as the earth. Perhaps he did not realize that his statements - the sun is twice as far from the moon as from the earth, the moon almost touches the earth, the sun is as big as the earth - do not harmonize well together.

59 See DK 59A72, 59A42(8), 59A1(8). The sources speak of "larger than the Peloponnese". Nevertheless, given the difficulties involved in the measurements at stake: the distances over land and over sea, the precise length of the shadow of a gnomon, and the angular diameter of the sun, and taking into account other ancient estimates of the sun's size (one foot: Heraclitus; as large as the earth: Empedocles), Anaxagoras' estimate falls within the range of our calculation as shown in Fig. 3, as argued in Couprie 2011, 189-200.

60 For these reasons I disagree with Kingsley 1994, 317, who states: "for Empedocles the earth was almost certainly spherical — or convex — in shape". Kingsley refers to Burkert 1972, 305: "the idea (A56)

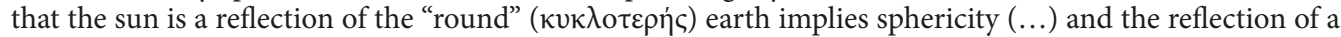
disc would appear distorted rather than perfectly round". Apart from the oddity of this argument, it would not be helpful to Kingsley, who rejects the very idea of the earth reflecting the sun.

61 Aëtius in Stobaeus, Eclog. 1.25.3e= DK 31A56= LM EMP. D126b.

62 See also the size of the sun in Fig. 4A (Bollack's drawing) and my comments on it. 
However, the above arguments put together there is little doubt that Empedocles considered the earth as flat.

\section{Bollack's attempt to draw Empedocles' cosmos}

Bollack is the only author I know of, who has attempted to visualize the cosmos according to Empedocles. His drawings have met with severe verdicts: "from the point of view of the most elementary optics totally erroneous diagrams", and "the extraordinary diagrams". ${ }^{63}$ Generally speaking, I agree with these judgements. Since my aim in this paper is not the evolution of the cosmos, which several of Bollack's drawings have to do with, I will only discuss his main picture that depicts the present situation of the egg-shaped tilted heaven. I will emphasize in particular the differences with my own drawings (see Figs. 5A and B). In Fig. 4A and B, I drew a copy of Bollack's main picture, next to his own explications, translated into English.

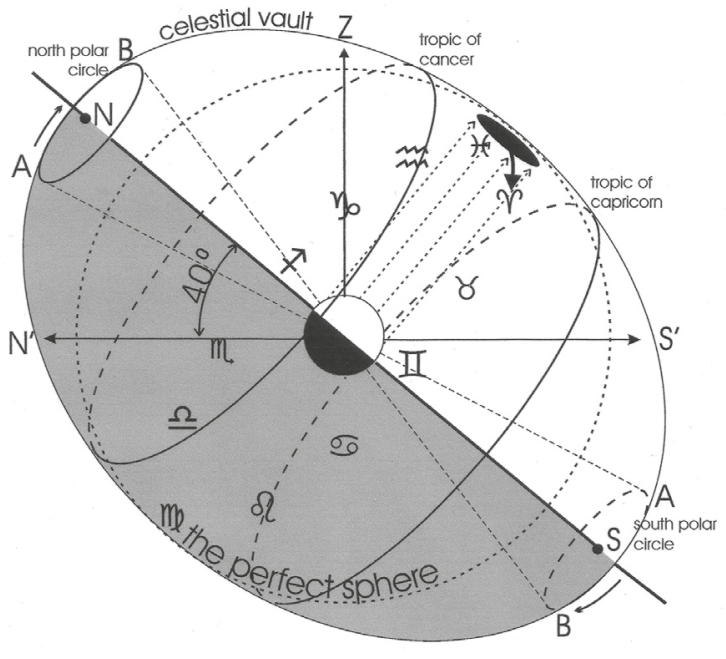

Fig. 4A. The egg-shaped cosmos after Bollack ${ }^{64}$

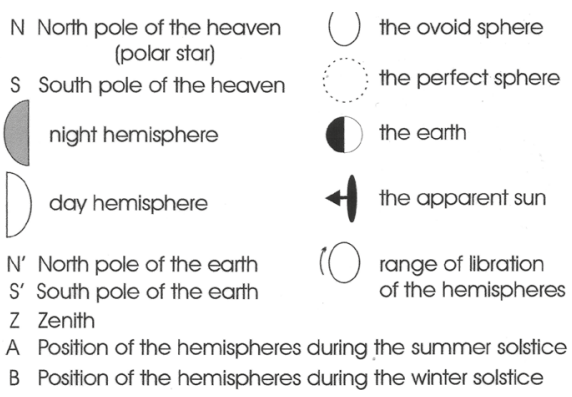

Fig 4B. Bollack's Legenda for Fig. 4A

Inside the ovoid shape Bollack has drawn "the perfect sphere", out of which the eggshaped cosmos emerged. The ecliptic is rendered by the signs of the zodiac. The arrow on the lentiform sun indicates the direction of the sun's orbit around the earth. The tilt of the heaven is $50^{\circ}$ from its originally upright position, in which egg-shaped heaven was supposed to be standing upright and its north pole $(\mathrm{N})$ was at point $\mathrm{Z}$. In the drawing, this tilt is indicated as $40^{\circ}$ in relation to the line N'S'. A serious flaw is that this line N'S' is identified with the polar axis of a spherical central earth (see also his explanatory notes on $\mathrm{N}^{\prime}$ and S' in Fig. 4B). Strangely enough this polar axis does not coincide with the celestial axis (NS), as it should do on a spherical earth. The reader had better forget the line N'S' and imagine the poles of the earth being located where the celestial axis cuts the earth. Bollack tried to visualize the two strange theories of text 12 that there

${ }^{63}$ Kingsley 1994, 317, n.7. and Wright 2001, 201.

${ }^{64}$ See Bollack 1992, I, 188 and 189. 
are two hemispheres, one of day and one of night, and two suns, one archetypal and the other its reflection. For a good understanding of his picture one should recognize that Bollack identifies the hemisphere of the day with the archetypal sun. The light of this hemisphere reflects on the earth and then concentrates in the sun as we see it. ${ }^{65}$ In the picture reproduced here as Fig. 4A, he only drew the reflection from the earth to the apparent sun (the four dotted and arrowed lines), while in another picture he also drew the lines of light from the hemisphere of day towards the earth. ${ }^{66}$ Bollack speaks of a "triple parcours", ${ }^{67}$ which means, I think, that in order to complete the picture, there should also be lines from the (apparent) sun pointing towards the earth, indicating the sunbeams. Although there is no text in the doxography to confirm this, Bollack makes the two hemispheres oscillate between two points (A and B in Fig. 4A) on the polar circles, apparently to provide for the polar night and day (see his last two explanatory notes in Fig. 4B). This attempt is not very successful, because in the drawing of Fig. 4A, the two hemispheres are in a position between these two extremes (during the equinoxes), which results in the strange phenomenon that someone at a pole of the earth (i.e. not one of the erroneously indicated poles N' and S', but one of the points where the celestial axis NS cuts the spherical earth) sees the hemisphere of the day on one side and the hemisphere of the night on the other. Another interpretation, involving that the upper and lower rims of the hemispheres are supposed to revolve on the polar circles from $\mathrm{A}$ to B and back, would not make it any better, because it would imply that at one of the poles it is always day while at the other it is night all year round. Bollack has chosen for a sun close to a spherical earth. He draws the sun the same size as the earth, which results in a huge sun with an angular diameter of about $15^{\circ}$, which is 30 times too big, the actual angular diameter of the sun being $0.5^{\circ}$. Given these flaws in his main picture, the above-quoted verdicts on Bollack's drawings are justified.

\section{A new picture of the sun, spiraling on an imaginary cylinder in an egg-shaped tilted cosmos}

After this long detour, we are finally in the position to make two pictures, Fig. 5A and B, of Empedocles' tilted, egg-shaped cosmos with the spiraling sun. Since someone might think they resemble Bollack's drawing, I will empasize the fundamental differences: 1) I omitted the erroneous features of the two hemispheres and the sun as a reflection. 2) For the above explained reasons, I drew a flat earth in the center of the cosmos. 3) I made the angle of tilt of the heaven $38^{\circ}$ in relation to the surface of the flat earth, corresponding with the latitude of Delphi, the earth's center. As required in text 14, the vertical distance from that center, to the heaven is shorter (albeit not much) than the horizontal distance. 4) In Fig. 5A, I drew the sun spiraling on an imaginary cylinder. In Fig. 5B, I drew the northernmost and southernmost positions during the two solstices, where the sun's movement is stopped and reversed by the crystalline sphere, as well as the sun's middle position during the equinoxes. 5) To make a drawing of the cosmos according to Empedocles, one must choose between two incompatibilities: the sun as big as the earth (text 20), and the sun at not a great distance from the earth (texts 16-19). For reasons mentioned above I have

65 Cf. Bollack 1992, III, 264-265.

66 See Bollack 1992, III, 270.

67 Ibidem. 


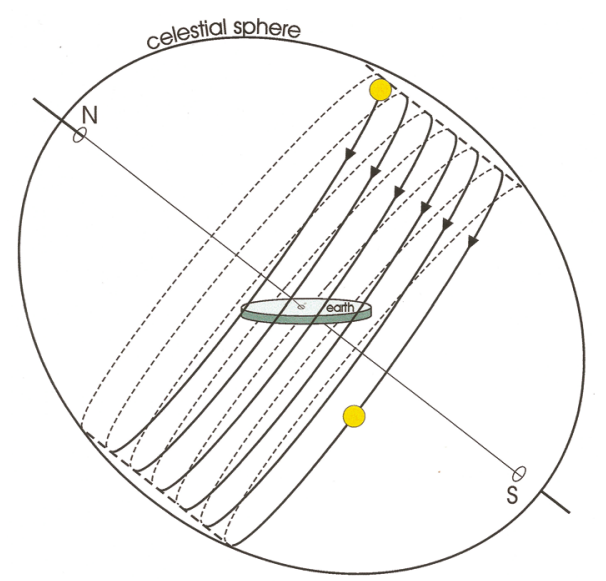

Fig. 5A. The sun spiraling around a cylinder in an egg-shaped and tilted cosmos

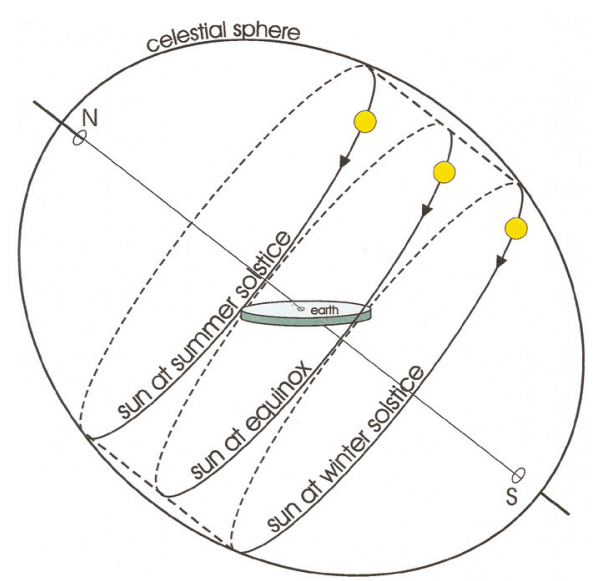

Fig. $5 B$. The orbits of the sun during the solstices and equinox

chosen for the option to neglect text 20. I drew the size of the sun still too big, but only for technical reasons: a sun with an angular diameter of $0.5^{\circ}$ would hardly be visible on the drawing.

We may conclude that, as a whole, Empedocles' cosmology is not very impressive, or at least confusingly transmitted by the doxographers. But we may also conclude that the idea of the sun spiraling on a imaginary cylinder was bright and original. It offered a clear - albeit erroneous - answer to the intriguing question as to why the sun is turning twice a year at exactly the same day and altitude in the sky.

\section{Empedocles and the movement of the moon}

The pictures of Fig. 5A and 5B show how relatively small the cosmos must be under the supposition of a flat earth (see also Fig. 3). As we have seen, Empedocles' image of the sun spiraling on the surface of an imaginary cylinder and touching the crystalline vault of the heavens during the solstices implies that the sun's orbit is located just inside the surrounding celestial vault. Since there is little or no room between the sun and the sphere of the stars, Empedocles most probably thought of the planets as wandering between the stars on the screen of the celestial vault, as seems to be confirmed by text 8 . This makes the sun and moon the only heavenly bodies that are not glued on or move on the celestial vault. We have seen in text 16, that according to Empedocles the moon is twice as far from the sun as it is from the earth. Although there is no text explicitly stating that the monthly movement of the moon could be described in similar terms as the annual movement of the sun, this seems to be indicated by the word $\dot{\varepsilon} \lambda$ i $\sigma \sigma \varepsilon \tau \alpha$ in a text about the moon:

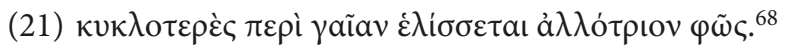

A circular borrowed light spirals around the earth.

68 Achilles Tatius, Introduction to Aratus 16=DK 31B45= LM EMP. D139. 


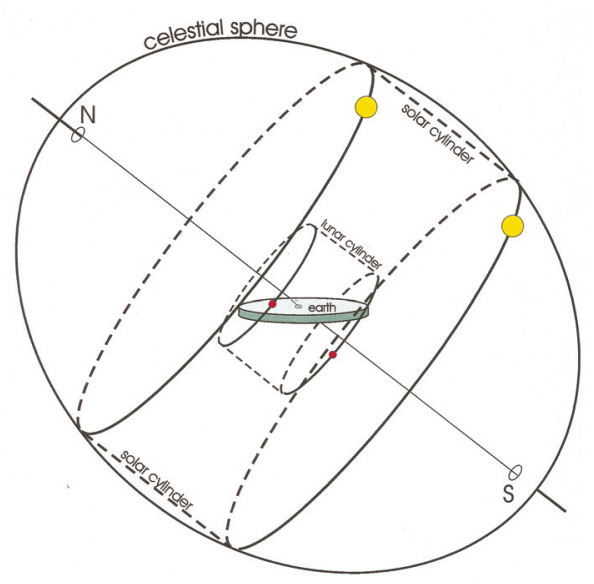

Fig. 6. The imaginary cylinders of the movements of the sun and moon

This text is mostly quoted because of its allusion to Homer ${ }^{69}$ in the words á $\lambda \lambda$ ótpıov $\varphi \tilde{\omega} \varsigma$ and its similarity with a text from Parmenides poem. ${ }^{70}$ In the context of this paper,

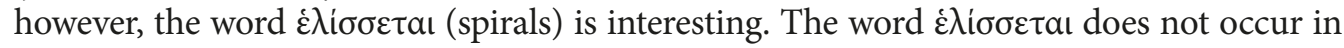
the parallel text of Parmenides, where the word á $\lambda \dot{\omega} \mu \varepsilon v o v$ (wandering) is used. This allows me to suggest that the moon must be thought to describe a spiral around an imaginary cylinder, similar to that of the sun. In order to be able to do so, we need to clarify the meaning of text 16. Of course, the moon is not always at the same distance from the sun: the sun is closest to the sun when it is new moon and farthest away from the sun when it is full moon. The easiest way to visualize that the distance of the moon to the earth is half the distance of the moon to the sun is to make the lunar cylinder one-third of the solar cylinder (see Fig. 6).

To avoid overloading the picture with spirals, I only drew the most extreme positions of the sun and moon. In a picture not reproduced here, Bollack also made an attempt to draw the moon's movement. ${ }^{71}$. He draws an arbitrary number of 22 parallel circles for the lunar movement during the month, while indicating by means of a spiraling ribbon under his picture that his intention is a spiral movement. Moreover, he does not make the moon move on a cylinder. Wright includes this attempt into Bollack's "extraordinary diagrams", but I think that in this case the verdict is too harsh. ${ }^{72}$

The highest elevation of the sun in Delphi, the flat world's center, is $75.4^{\circ}$ (at the summer solstice) and the lowest $27.8^{\circ}$ (at the winter solstice). The moon's orbit is inclined by $5^{\circ}$ in relation to the ecliptic, so the highest and lowest possible elevations of the moon during the month are about $80.4^{\circ}$ and $22.8^{\circ}$. These data result in an imaginary cylinder of the moon that does not reach to the boundaries of the egg-shaped heaven, as is shown in Fig. 6. Therefore, the reason for the moon's turnings at both ends of its spiraling orbit cannot be that the moon is hindered by the crystalline sphere. Here the doxography leaves us, so we only can guess.

${ }^{69}$ Cf. Homer, Od. 18.219, where the expression ả $\lambda \lambda$ ót

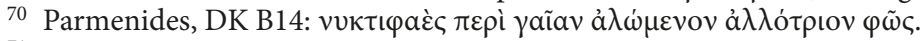

${ }^{71}$ Bollack, 1992, III, 298-299.

72 Wright 2001, 201. 
It is less relevant for the movements of the sun and moon as discussed in this paper, but I think we should consider the sun disk-shaped or lentiform, ${ }^{73}$ as is handed down for the moon:

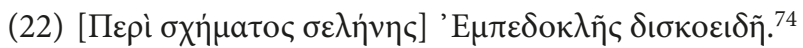

[On the shape of the moon) Empedocles (declares that it is) disk-shaped.

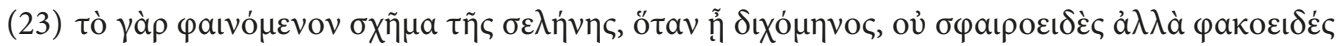

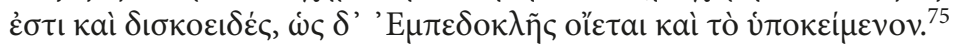

The apparent form of the moon when it is full is not that of a sphere but of a lentil and a disk, just as Empedocles thinks that also in reality this is its shape. ${ }^{76}$

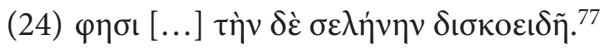

He says (...) that the moon has the form of a disk.

To get a better idea of the disk-shaped sun and moon, the reader might imagine the little circles of the sun and moon in Figures $5 \mathrm{~A}$ and $\mathrm{B}$ and 6 to be rotated by $90^{\circ}$, so that they are "looking at the earth".

\section{The movements of the sun and moon according to Anaximander}

It can be argued that Empedocles was not the only Presocratic thinker who made the sun (and moon) move on an imaginary cylinder. In great lines, the cosmos according to Anaximander has the following main characteristics. He believed that the earth was flat, shaped like a column-drum. He considered the sun and moon as huge wheels lying aslant while they rotate around the earth. These wheels are usually understood as representing the daily orbits of the sun and moon around the earth and their lying aslant as resulting from the tilt of the celestial axis. We cannot see the heavenly wheels, because they are made of (thick) air. Inside the wheels is fire, which we also cannot see, except for one opening where the fire shines through. These openings are what we call the sun and moon. The stars are closest to the earth, the sun farthest away and the moon in between. There is no indication in the texts on Anaximander of a celestial vault. The distances from the central earth to the heavenly bodies are 9, 18, and 27 earth-diameters respectively, according to a generally accepted reconstruction of the numbers mentioned in the doxography. ${ }^{78}$

In the context of this paper, I will concentrate on the movements of the wheels of the sun and moon. Since they represent the daily movements of the sun and moon, of

73 See, e.g. Bollack's drawing, here redrawn as Fig. 5, and Wright's remark: "No notice is extant on the shape of the sun for E., but I suspect it was lentiform too" (Wright 2001, 201).

74 Aëtius 2.27.3 = DK 31A60, not in LM.

75 Plutarch, Quaest. Rom. 101, 288B = DK 31A60 = LM EMP. D135a.

76 All editions of the Greek text have a comma between olictaı and kaì. I left it out, because I follow the

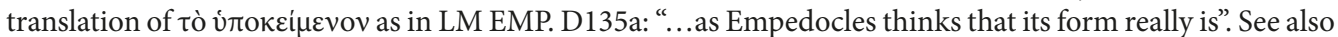

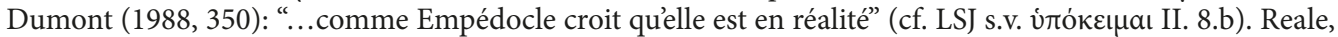
however, translates: “...come ritiene Empedocle e come è in realtà", which makes no sense, because Plutarch must have been acquainted with Aristotle's convincing argument for the sphericity of the moon given the shapes of its phases (Cael. 291b19-22).

77 Diogenes Laërtius 8.77 = DK31A1(77) =LM EMP. D135b.

${ }_{78}$ The most relevant texts, not quoted here in full, can be found in DK 12A10, 12A11, 12A18, 12A21, 12A22, and 12A25 (LM ANAXIMAND. D7, D8, D20, D22-24, D26, D29). 


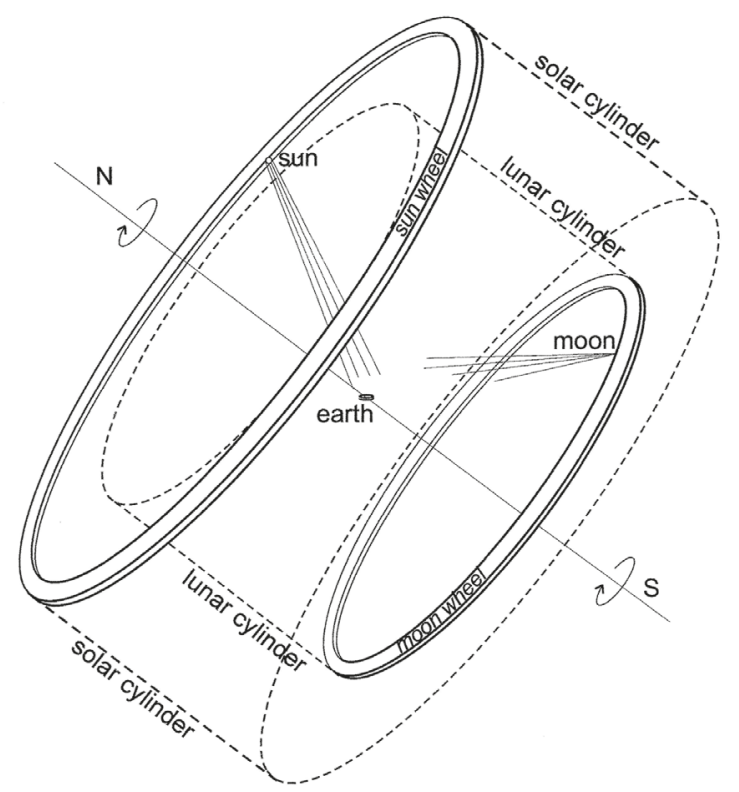

Fig. 7 - The movements of the sun and moon according to Anaximander

which they are, so to speak, a materialization, the celestial axis is the axis of the heavenly wheels as well. These wheels must be imagined not only to rotate, but also to slide up and down the celestial axis, the sun wheel during the year, the moon wheel during the month. Sliding up and down the celestial axis in this way, the wheels of the sun and moon move on two imaginary cylinders, as shown in Fig. 7. The spiraling movements of the sun and moon (i.e. the holes in their wheels) result from this up and down sliding movement of the celestial wheels.

Although they have much in common, there are four important differences between Anaximander's and Empedocles' conceptions. 1) Anaximander's celestial wheels do not occur in Empedocles' cosmos. 2) Anaximander's cosmos is much bigger than that of Empedocles. While Empedocles' moon almost touches the earth, Anaximander's moon is at 18 earth-diameters distance and while Empedocles' sun is three times as far as the moon, Anaximander's sun is at 27 earth-diameters distance. If we were to draw Anaximander's cosmos on the same scale as that of Empedocles, it would not fit in the page at all. This means that in the standard interpretation of Anaximander's numbers it must be taken for granted that he did not realize that the cosmos cannot be that large, given the flatness of the earth..$^{79} 3$ ) That the daily orbits of the sun are always equally wide results for Empedocles from its moving along an imaginary cylinder, while for Anaximander it is the consequence from his conception of the sun-wheel. The same holds, mutatis mutandis, for the daily orbits of the moon. 4) For Empedocles, the sun's spiral movement always stops

79 The standard interpretation of Anaximander's numbers as indicating the distances of the heavenly bodies has been recently questioned (see Thibodeau 2017). If the numbers would not indicate celestial distances, Anaximander's cosmos could be much smaller and would be much more like that of Empedocles as in Fig. 6, except for the crystalline celestial vault. A thorough discussion of Anaximander's numbers would take us far beyond the scope of this paper. See Couprie 2018, 75-98. 
and returns at the same places in the heaven and on the same days of the year because it is impeded by the crystalline vault. In Anaximander's cosmos, there is no celestial vault, as far as we know. Accordingly, one source gives another cause for the turnings of the sun:

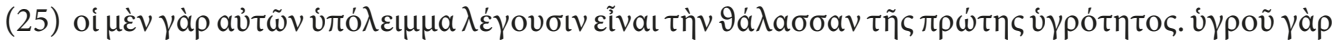

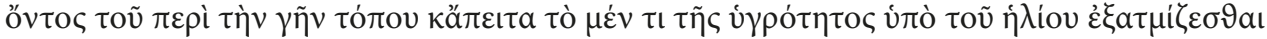

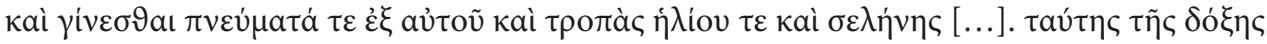

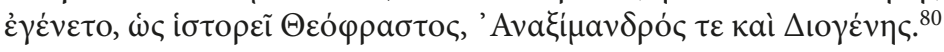

Some of them say the sea is what is left of the primeval moisture. For the region about the earth was first moist, and then part of the moisture was evaporated by the sun, and there arose from it winds and the turnings of the sun and moon (...). Those who held this view, as Theophrastus reports, were Anaximander and Diogenes.

This text is an interpretation of a similar one in Aristotle, where he speaks in general terms of "those ancients who were more versed in human wisdom" (by contrast with the theologians). ${ }^{81}$ The explanation of the sun's turnings in text 25 implies a kind of reciprocal causality: the sun makes the moisture evaporate, which on its turn generates winds that cause the turnings of the sun. It also looks remarkably like the Stoic explanation of the turnings of the sun, given in text 4 , which seems to mean that this explanation goes back to Anaximander. 82

\section{References}

Bicknell P. J. The Shape of the Cosmos in Empedocles. La Par. del Pass. 1968, 23, 118-119.

Bollack J. Empédocle I-III. Paris, Gallimard, 1992.

Bottler H. Pseudo-Plutarch und Stobaios: Eine synoptische Untersuchung. Göttingen, VandenHoeck \& Ruprecht, 2014.

Burkert W. Lore and Science in Ancient Pythagoreanism. Cambridge, Ma, HUP, 1972.

Couprie D. L. Heaven and Earth in Ancient Greek Cosmology. From Thales to Heraclides Ponticus. New York, Springer, 2011.

Couprie D. L. When the Earth Was Flat. Studies in Ancient Greek and Chinese Cosmology. New York, Springer, 2018.

Diels H. Doxographi Graeci. Berlin, De Gruyter, 1879 (abbreviated as Dox).

Diels H., Kranz W. (ed., transl.) Die Fragmente der Vorsokratiker. Zürich - Hildesheim, Weidmann, ${ }^{6} 1951$ (abbreviated as DK).

Dumont J.-P. (transl.) Les Présocratiques. Paris, Gallimard, 1988.

Furley D. Cosmology, in: K. Algra, J.Barnes, J.Mansfeld, M.Schofield (eds). The Cambridge History of Hellenistic Philosophy. Cambridge, CUP, 2010, 412-451.

Gemelli Marciano M. L. (ed., transl.), Die Vorsokratiker 2. Berlin, Akademie Verlag, 2013.

Graham D. W. (ed., transl.) The Texts of Early Greek Philosophy. Cambridge, CUP, 2010.

Guthrie W. K. C. A History of Greek Philosophy, II: The Presocratic Tradition from Parmenides to Democritus. Cambridge, CUP, 2003.

Heath T. Aristarchus of Samos. Oxford, Clarendon Press, 1913.

Kingsley P. Empedocles' Sun. CQ 1994, 44.2, 316-324.

Kočandrle R. The Cosmology of Anaximenes. HPhQ 2019, 36.2, 101-119.

Laks A., Most G. W. (eds, transl.) Early Greek Philosophy. Cambridge MA, HUP, 2016 (abbreviated as LM). Mansfeld J. (ed., transl.) Die Vorsokratiker II. Stuttgart, Reclam, 1986.

${ }^{80}$ Alexander of Aphrodisias, In Arist. Mete. 67, 1-2=DK 12A27 = LM ANAXIMAND. D35b.

81 Aristotle, Mete. 353b6-11 = DK 12A27 = LM ANAXIMAND. D35a.

82 In the context of the discussion of text 1, MR 557 refers to Anaximander's cylindrical (drumshaped) earth. The shape of the earth, however, has nothing to do with the cylindrical shape of movement of the sun and moon on an imaginary cylinder. 
Mansfeld J. Cosmic Distances: Aëtius 2.31 Diels and Some Related Texts. Phron. 2000, 45, 175-204.

Mansfeld J., Runia D. T. Aëtiana: The Method and Intellectual Context of a Doxographer. Volume Two, The Compendium. Leiden, Brill, 2009 (abbreviated as MR).

McKirahan R.D. Philosophy Before Socrates. Indianapolis - Cambridge, Hackett Publishing Company, 2010.

Mulder E. Sonne, Mond und Sterne. Eine Entdeckungsreise in die Astronomie. Stuttgart, Freies Geistesleben, 1994.

Reale G. (ed., transl.) I Presocratici. Firenze, Bompiani, 2017.

Tannery P. Pour l'histoire de la science Hellène. Paris, Alcan, 1887.

Thibodeau P. Anaximander's Model and the Measures of the Sun and Moon. JHS 2017, 137, 92-111.

Wachsmuth C. (ed.) Ioannis Stobaei Anthologii libri duo priores qui inscribe solent Eclogae physicae et ethicae, Volume I. Berlin, Weidmann, 1884.

Wright M. R. Empedocles: The Extant Fragments. London, Bristol Classical Press, 2001.

Received: October 19, 2019

Accepted: February 10, 2020 